(Contribution from the Research Laboratory of Physical Chemistry, Massachusetts Institute of Technolngy, No 148)

\title{
THE THERMODYNAMIC PROPERTIES OF METHANE
}

By Frederick G. Keyes, Robert S Taylor and Leighton B. Smith

1 Introduction The Vapor Pressure of Methane. There are very few published data for the vapor pressure of liquid methane Olszewski's results extend from the critical temperature to the freezing point, but the pressures are several atmospheres greater than the recent measurements of Cardoso ${ }^{2}$ in the interval $-844^{\circ}$ to $-970^{\circ}$ The critical pressure, for example, obtained by Olszewsk 1 is $549 \mathrm{atms}$ at a critical temperature given as $-818^{\circ}$ whereas Cardoso gives $4560 \mathrm{atms}$ at $-8285^{\circ}$ No other measurements have been found in the literature

In the case of methane there are two very material difficulties connected with securing accurate vapor pressure values Thus it is necessary to maintain and measure temperatures from $-80^{\circ}$ to $-180^{\circ}$ and insure that the temperature readings lie on the absolute scale of temperature The latter objective is by no means easy to insure, since the comparisons of secondary standard thermometers with the gas scale have not reached a stage where satisfactory concordance has been attained between various investigators The relation of the platinum resistance thermometer to the gas scale, for example, has been shown by Henning ${ }^{3}$ not to be the same below zero as above zero where the Callendar formula applies In fact, no two of Henning's eight platinum resistance thermometers appeared to give identical readings at all temperatures below zero, although the $\delta$ constants of Callendar, obtained by using $0^{\circ}, 100^{\circ}$, and $4194^{\circ}$ for some of the thermometers, were almost identical The general inference was that the differences between the gas scale and the Callendar formula temperatures of the platinum resistance thermometers were very markedly affected by small variations in the temperature coefficient of the platinum wire

1 Olszewsk1, C. r 100, 940, 1885

2 Cardoso, Jour de Chim et Phys 13, 332, 1915

3 Henning, Ann d Phys 40, 635, 1913 
The further need in accurate low temperature work is a constant temperature bath whose temperature can be changed at will from zero to the lowest temperatures required The use of liquids bolling under constant pressure for this purpose has been highly developed in the Le1den cryogenic laboratory of Professor Onnes, but is not as convenient as desirable owing to the necessity of changing the bath liquids for studies covering long temperature ranges It $1 \mathrm{~s}$, in addition, necessary to vary and maintain constant the pressure over the boiling liquids The device used by Henning in the paper referred to above consisted of a test tube, submerged in a bath of petroleum ether, into which liquid air is dropped as required Evidently a bath of this description would be troublesome to use where observations are to be made requiring concentration of attention on the details of the physical measurements

The purity of the methane to be used is of paramount importance For the present work samples of the methane were employed prepared as described in the preceding paper on the equation of state of methane

In view of the uncertain status of the behavior of the platinum resistance thermometer at low temperatures an investigation had already been made in the physics department laboratories of this Institute of the relation between the scales of the platinum resistance thermometers actually used in the present investigations with the gas scale The freezing points of a number of substances lying between zero and the bolling point of oxygen were also measured in terms of the constant volume hydrogen gas scale to serve as calibration temperatures

The question of the thermodynamic scale is of particular importance at low temperatures, since the effect of a given error in temperature measurements is of increasing significance as lower temperatures are approached Thus for example, $01^{\circ}$ at the 1ce point, 27314 , 1s an error somewhat greater than 1 per 3,000 , whereas $01^{\circ}$ at the bolling point of oxygen, 9020 , is of more than three times this magnitude The temperatures recorded in the present paper are, then, those obtained by means of a platinum resistance thermometer compared directly with the constant volume hydrogen thermometer at a number of temperatures between zero and the normal bolling point of oxygen 
2 Apparatus Details. The apparatus of first importance is the cryostat represented to scale in Fig 1 It consists of two pyrex Dewar tubes, one of which A serves to contain liquid air, or, under certain conditions, hquid ammonia Support for the larger tube is provided by means of a brass ring encircling the flask and attached thereto are three brass strups screwed to the cast-iron

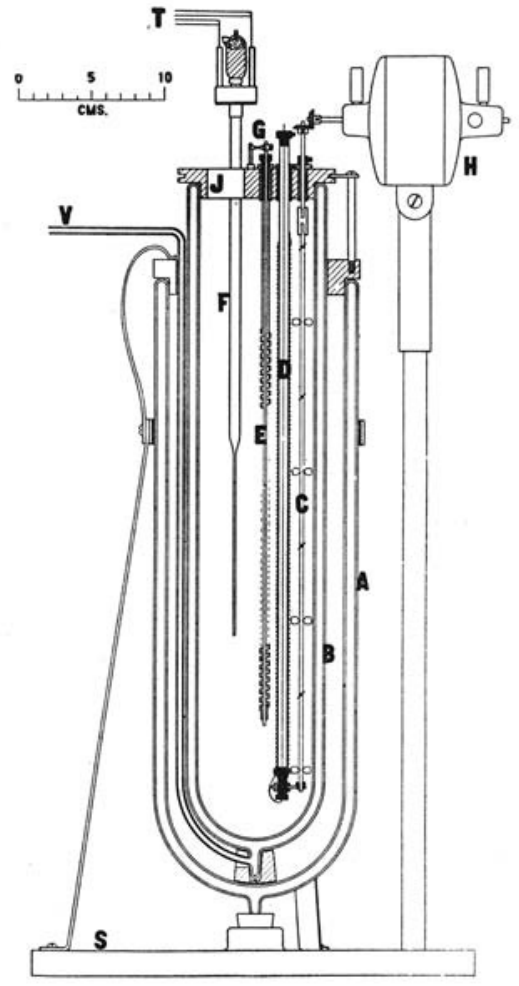

Fig. 1

base $\mathrm{S}$ The cast-1ron base also serves to carry the support rod for the motor $\mathrm{H}$ used to strr the contents of the bath itself The inner Dewar tube is supported in the larger tube by means of an asbestos wood cover into which the smaller tube is cemented The inner Dewar tube is provided with a cork support at its tip, from which a tube $\mathrm{V}$ leads to a source of hydrogen or to a vacuum. 
The outer tube is silvered except for a rectangular strip which permits a view of the interior The inner Dewar tube is supplied with a cover which serves as a support for the stirrer, heater, temperature regulator and platinum resistance thermometer The cover of hard rubber is held firmly in place by three bolts carrying tongues of brass which fit into a slot turned into the periphery of the hard rubber cover An opening is also provided at $\mathrm{J}$ for the introduction of the apparatus upon whose contents observations are to be made It 1s, of course, essential that the introduction of heat by conduction should be a minimum and for this reason the sturrer rod $\mathrm{C}$ is interrupted by a hard rubber connector just under the cover The shank of the thermometer is of monel metal turned to about $02 \mathrm{~mm}$ thickness, and having the silver sheath containing the platinum wire silver-soldered thereto The regulator consists of a $3 \mathrm{~mm}$ width and $075 \mathrm{~mm}$ thickness invar-brass thermostat metal * This is wound in a helix as ind1cated and the upper end soldered to a thin brass tube The lower end carries, floating, a fine monel rod passing loosely through a hard rubber bushing shown shaded at $G$ Here two platinum contacts are arranged and as the helix winds and unwinds, due to temperature changes, contact is made and broken The sens1tivity 1 s limited by the pressure necessary to make electrical contact The maximum sensitiveness which has thus far been attained at the lower temperatures is about $01^{\circ}$ The platinum resistance thermometer, however, indicatıng $0001^{\circ}$ makes it easy to secure a temperature constant to $001^{\circ}$ The combination of hand regulation with the automatic requires an operator to watch the galvanometer of the resistance bridge and manipulate resistances in accordance with the deflections of the galvanometer The bimetallic helix, on the other hand, would have great sensitivity were it not for the really considerable pressure needed for good electrical contact It is hoped that in time means for surmounting the latter difficulty will be evolved, since it is most convenient to have the bath automatically regulated

The heater consists of a very thin steel, or preferably monel, tube upon which is wound the resistance wire over thin mica

* This excellent material was obtained in several thicknesses and lengths through the kindness of the $\mathrm{H}$ A Wilson Co of Newark, N J 


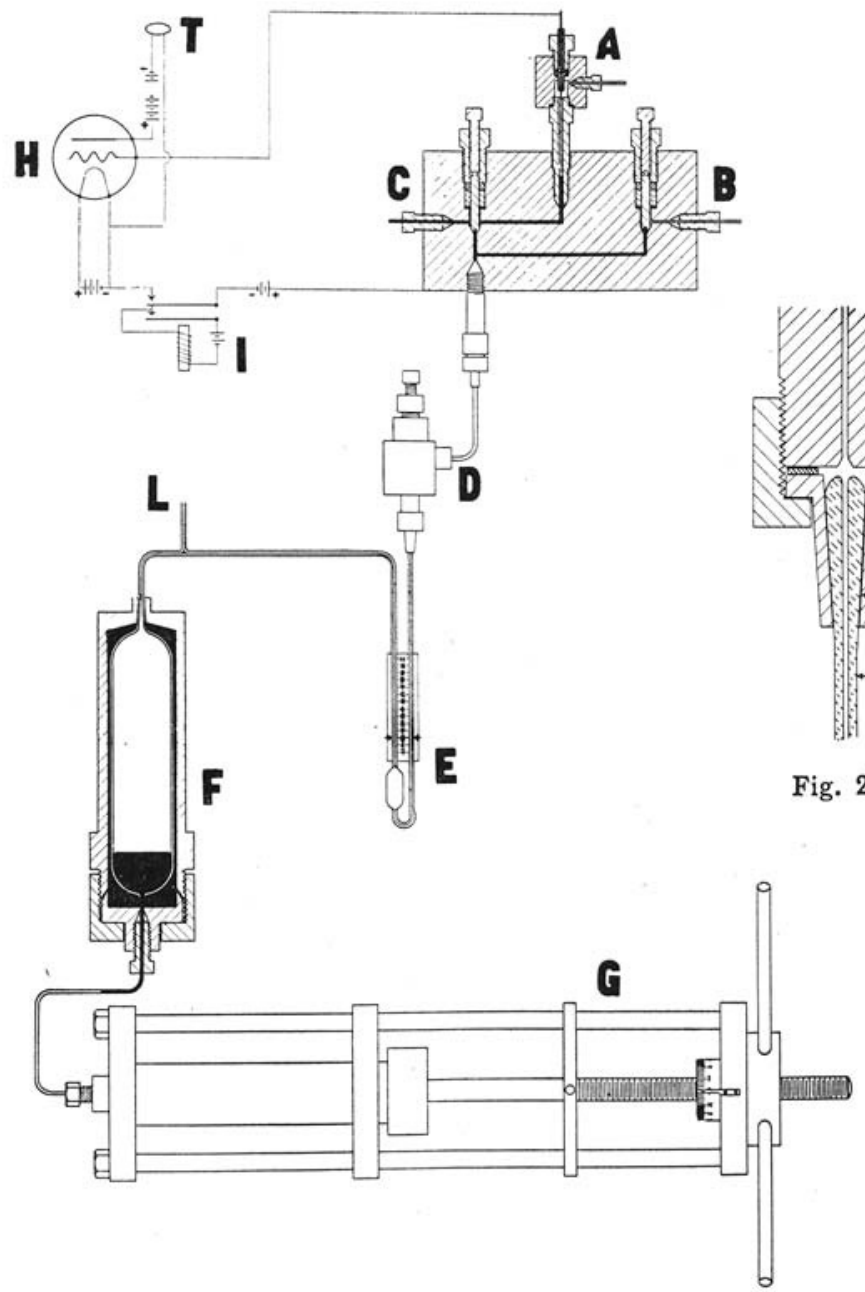

Fig. 2 
Talc plugs serve to insulate the free end of the wire which passes through the center of the supporting tube

The method of operating the bath consists in adjusting the pressure of hydrogen in the interspace of the Dewar tube B until sufficient cooling of the bath fluid is secured to balance the mean value of the heating current For the lowest temperatures, for example, as good as possible conductivity of the interspace is required and a centimeter pressure of hydrogen is sufficient At high temperatures, on the other hand, a relatively low pressure is necessary on account of the greater difference in temperature between the contents of the cryostat bath $B$ and the surrounding liquid air For temperatures above $-30^{\circ}$ it is best to use liquid ammonia in the outer dewar tube, and thus any temperature in the range between $0^{\circ}$ and $-180^{\circ}$ may be eas1ly established and maintained

The vapor pressures were measured in two separate preces of apparatus Pressures above several atmospheres were measured at the time the densities of the liquid were being measured, while a special apparatus was used for the lower pressures down to the triple point In $\mathrm{F}_{1} \mathrm{~g} 2$ is represented the block $\mathrm{C}$ as described in the preceding paper on the equation of state for methane $A$ is the mercury oil contact, the orl lead connecting with the piston pressure gauge $\mathrm{C}$ leads to the mercury volume-measuring injector and $B$ leads to the vacuum pump The electrical circuit for indicating mercury contact at the oil junction within A consists of an audion bulb, induction coil primary, dry batteries and telephone

The steel stopcock D serves to shut off the mercury in the pyrex glass volume-measuring apparatus* $\mathrm{E}$, which connects by

* The coefficient of temperature expansion of pyrex glass has not been measured at low temperatures The following equation for the true volume at any temperature $t$ is based on the mean expansion measurements in a weight-thermometer of pyrex glass between 0 and 100 , and 100 and $218^{\circ}$

$$
V_{i}^{\text {pyrex glass }}=V_{\mathrm{o}}\left(1+968 \times 10^{-6} t+3.11 \times 10^{-0} t^{2}\right)
$$

The error that extrapolation to $-180^{\circ}$ may introduce in the measurements of the specific volume of liquid methane is inconsiderable unless the coefficient of expansion of pyrex glass is widely different from soda glass in its general expansion behavior This is not inferred since its expansion properties are quite similar to soda and other glasses above zero.

The expansion of the volumenometer with pressure was determined at zero degrees by blank measurements with the bell $\mathrm{F}$ sealed off from the 
$075 \mathrm{~mm}$ bore pyrex glass tubing at one side with the steel $\operatorname{cock}^{* *}$ $D$ and at the other with the pyrex glass bell $(275 \mathrm{~cm}$ diameter and $125 \mathrm{~cm}$ long) enclosed in the steel case $\mathrm{F}$ The capillary lead $\mathrm{L}$ is used to exhaust the glass portion previous to the introduction of the methane The compressor $G$ connecting with $\mathrm{F}$ serves to force methane into $\mathrm{E}$ where the liquid volumes were measured It is percelved that the apparatus consists of a constant volume portion $\mathrm{E}$, which can be filled with liquid methane at any temperature in the liquid region by manipulating the mercury injector $G$ transferring methane from the reservorr $F$ at ordinary temperatures

The volume of $\mathrm{E}\left(15798 \mathrm{c} \mathrm{c}\right.$ at $\left.0^{\circ}\right)$ together with the capillary leads was determined by filling with mercury and weighing. The volume of the bell within $\mathrm{F}$ (about $75 \mathrm{cc}$ ) was measured by means of the piston $G$ The injector $G$ (total volume capacity $56 \mathrm{c} \mathrm{c}$ ) was calibrated by weighing the mercury ejected for each five turns of the nut advancing the piston The position of the piston was indicated by a "cyclometer" giving the number of whole turns, and the fractions of a turn, on the nut whose periphery was divided into one hundred divisions The piston was so adjusted that practically at its maximum inward travel the mercury stood at a mark on the capillary of determined volume per unit length above $F$ The glass bell was, of course, so

volumenometer Correction could, therefore, be made for the stretch of $\mathrm{E}$ with pressure although this was not determined as a function of the temperature Previous experience with soda glass above zero has shown that the temperature coefficient of the pressure stretch is very small withm the elastic limits of the glass

**In Fig 2a is represented an enlarged drawing of the method employed to connect the steel and glass The glass capillary $F$ is thickened to an inverted cone shape and ground to fit the steel piece $D$ The member $D$ is then warmed and a thin layer of a cement made from shellac which has been digested on a water-bath with fifteen per cent of North Carolina oil of tar, is wiped over the ground surface The glass member is now seated in the steel part $D$, turning the glass member in its seating position until the cement is squeezed out and the ground surfaces in as close contact as possible Connection can now be made with any other part of the steel apparatus, as represented at $A$, by means of a union $B$, using an annealed aluminum disk $C$ The glass capillary $F$ should be joined in situ to the remaining portion of the glass apparatus to avord strans at the rigid steel construction The joint of the steel and glass bell $F$ is made in the same manner as described The joints described are vacuum tight, resist the action of mercury and hold against pressure to the limit of the glass They cannot be used, however, above $100^{\circ}$ 
proportioned (75 c c capacty) that when the piston was withdrawn to the complete outward travel of the screw, mercury sealed the lower end of the bell Methane from the storage globe was now passed over into a measuring burette, similar to the one used in loading the piezometer employed in measurng the isometrics of the gas phase, and condensed finally in $\mathrm{E}$ at the temperature of liquid oxygen The capillary lead at $L$ was then sealed and the gas remaining in the leads between $\mathrm{L}$ and the measuring burette pumped off and measured Before $\mathrm{E}$ was allowed to warm to room temperature the mercury was lowered in $\mathrm{F}$ to the maximum by withdrawing the piston of $G$ The methane could then be safely allowed to evaporate from $\mathrm{E}$, filling a space of about $56 \mathrm{c} \mathrm{c}$ and producing a total pressure of only $10 \mathrm{atms}$ at ordnary temperatures

To make a measurement of the specific volume the volumenometer $\mathrm{E}$ was brought into the cryostat already described A glass scale divided into millimeters was placed back of the volumenometer serving to give indication of the position of the level of the meniscus of liquid methane relative to two etched marks on the capillary extensions from the volumenometer bulb At a fixed temperature mercury was forced over from a second mercury injector communicating from B until the meniscus was just about at the level of the cover of the cryostat and fixed in position by closing the steel stopcock D By means of G methane was forced to condense in $\mathrm{E}$ unt1 the liquid methane menisc1 were about at the two etched marks on the volumenometer stems A fixed volume of liquid methane was, therefore, confined by the gas phase present in the capillary leads The total mass of methane was known after sealing at $L$ and the volume, temperature and pressure of the methane existing in the gas phase, from the reading of the position of the piston of the injector $\mathrm{G}$ and the volume of the glass cap1llary tubing By means of the equation of state the mass of this known total gaseous volume could be computed, and the mass of the liquid methane of known volume in $\mathrm{E}$ deduced Before changing the temperature of the cryostat the steel cock D could be opened and an observation made of the vapor pressure In this manner practically the whole temperature range of the existence of the liquid phase could be measured The critical temperature was ascertained and also the critical pressure 
In the procedure described no mention has been made of the influence of adsorption in remoring methane from the phase under observation The volumenometer $\mathrm{E}$ was exhausted at $360^{\circ}$ for several hours previous to admitting the methane No certainty is afforded that adsorption did not take place, but freeng the glass surface from adsorbed mo1sture appears, from general experience, to minimize the adsorption of the permanent gases * The.bell $\mathrm{F}$ could not be evacuated hot, so that no certan knowledge is avarlable as to the amount of methane adsorbed The total

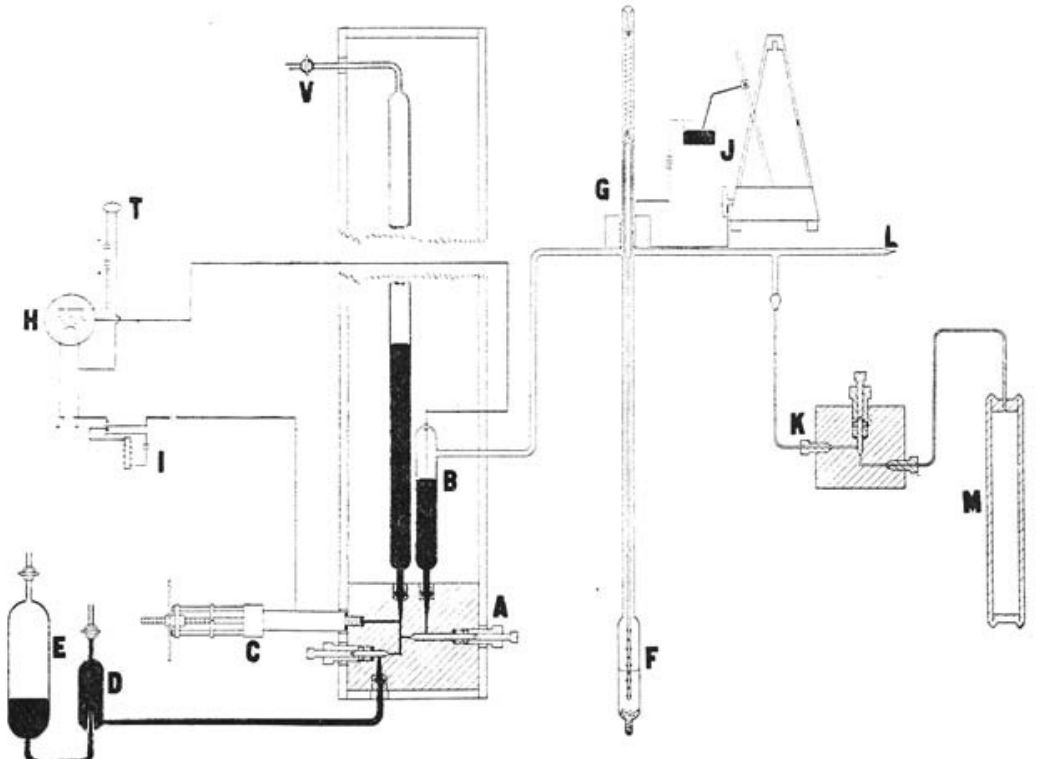

Fig. 3

mass of methane was, however, sufficiently large, so that, if ten molecular layers of methane were adsorbed, the effect would scarcely be detectable with the accuracy attainable in the volumenometer measurements

The measurements of saturation pressure below several atmos-

* It was shown by Eumorphopoulos (Proc Roy Sc1 $90 \mathrm{~A}, 189$, 1914) that only by repeatedly heating and rinsing with dry nitrogen could the coefficrent of volume increase with temperature at constant pressure be made reproducible Isometric measurements with ammonia in this laboratory have indicated that adsorption is greatly minımized by long baking out of the glass at the best vacuum obtanable 
pheres were carried out in a specal apparatus, since the piston gauge is not suitable for low-pressure measurements The general apparatus is represented in Fig 3 The manometer tubes were selected of uniform bore, $15 \mathrm{~cm}$ in outside diameter and the actual diameter along the length determined by weighing mercury taken from successive intervals along the length of the longer leg The short leg of the manometer was provided with a finely pointed platinum wire sealed into the closed end and the diameter accurately determined at the section in the plane of the point With the true tube diameters a table was then computed giving the correction for capillary depression for different heights of mercury The corrections for capillary depression with tubing $15 \mathrm{~cm} \mathrm{I} \mathrm{D}$ will rarely exceed a few hundredths $\mathrm{mm}$ with tubes of moderate uniformity of bore Each manometer tube was ground to a seat in the steel block $A^{*}$ having steel cocks to cut off the two legs of the manometer and the levelling reservoir $\mathrm{E}$ The mercury in the reservoir $\mathrm{E}$ was passed through the trap $\mathrm{D}$ to prevent air from gaining access to the manometer tubes, and all connections were of glass Compressed air and vacuum served to manipulate the entrance and exit of mercury to the manometer, while fine adjustment was secured by means of the mercury piston injector C. The purpose of the platinum contact B in the short arm was to a1d in observing equilibrium of the methane in the container $\mathrm{F}$ and to save continually reading the mercury level in the short arm, since the reading of the level when contact just makes is reproducible to the limit of sensitiveness of the cathetometer $(002 \mathrm{~mm})$

The methane container during the actual measurements consisted of the tube $\mathrm{F}$ contanning an electro-magnetically operated glass stirrer as indicated The coil $\mathrm{G}$ was energized periodically by means of the metronome contacting device represented It

* The ground joints and block were warmed and set with the shellac cement, as described in the case of the steel-glass joint represented in Fig 2. An enlarged and threaded portion was produced in the steel block above the ground cone, for the purpose of preventing the tubes floating off their seat The tubes themselves were enlarged, as indicated, at a point where they would come within the threaded part and at the time of seating the tubes, when both glass and steel were hot, cement was poured into the threaded cavity With the construction here indicated the glass cones can be made and ground so that the bore of the glass coincides with the communicating hole in the steel, eliminating thereby any tendency to trap gas 
is, of course, necessary to adjust the penod of the metronome to the elastic characternstics of the spring by which the stirrer is suspended The soft iron rod constituting the armature is enclosed in glass just below the eye used to fasten the lower end of the spring.

The exhaustion of the apparatus took place through the lead at L, while the long leg of the manometer was exhausted or exposed to the atmosphere at $\mathrm{V}$ depending on the magnitude of the pressure to be measured The methane to be used in the measurements was transferred from the glass storage globes to the steel tube container $M$ provided with a steel block carrying a cock and lead $K$ Methane was condensed in $M$ by means of liquid air, after having been thoroughly exhausted Connection was made to the glass apparatus by means of the shellac cement. When the entire apparatus was thoroughly exhausted to the cock in the steel block $\mathrm{K}$, the tube $\mathrm{F}$ was brought into the cryostat, adjusted to the lowest temperature $\left(-180^{\circ}\right)$, and by opening the cock of the steel methane container, a quantity of methane was condensed in $\mathrm{F}$ for the measurement of the vapor pressure The exhausting lead $\mathrm{L}$ carried a stopcock in order to permit of pumping the methane between successive measurements, thus insurnng the absence of foreign gas, although the methane during its introduction into the container $M$ was treated to remove all permanent gases At the conclusion of a day's measurements, the methane could be transferred from the tube $\mathrm{F}$ to the container $\mathrm{M}$ and held under pressure for future measurements

3 The Temperature Measurements. The temperatures recorded should lie on the absolute or thermodynamic scale and, while numerous investigations have resulted in fixing with considerable certainty the thermodynamic scale above zero, the temperature scale below zero, as already stated, is by no means as completely investigated The difficulties, indeed, are increased in the region below zero, due to the difficulties of refrigeration, lack of convenient cryostats and errors introduced in the gas thermometry by adsorptive effects The latter are of increasing significance as the temperature is lowered and are, moreover, par- 
ticularly difficult to investigate quantitatively Unfortunately, as Henning has shown, the platinum resistance thermometer does not follow the Callendar formula in its relation to the thermodynamic scale below zero Moreover, owing to the fact that the wire contracts on cooling, it is not easy to devise a method of winding which will avo1d the production of strains Above zero, on the other hand, the wire expands and the tension of the wire on its support is relieved

Owing to the importance of an accurate knowledge of the true temperature indications of the particular platmum thermometer employed in the present work, an extended comparison was made durectly with the constant volume hydrogen thermometer employed in an investigation of the low temperature scale by Keyes, Townshend and Young in this Institute The actual curve, ( $F_{1 g} 14$ of their paper), shows the difference between the Callendar formula platinum resistance thermometer temperatures and those of the quartz hydrogen thermometer of constant volume The hydrugen gas scale temperature of the boilng point of pure oxygen at $76 \mathrm{~cm}$ was found to be -18294 as compared with -18293 of Onnes ${ }^{4}$ and -18297 of Henning ${ }^{5}$ The boiling point of carbon dioxide at $76 \mathrm{~cm}$ was similarly found to be -7853 as compared with -7852 found by Henning ${ }^{5}$

4 The Vapor Pressure Measurements. The measurements at higher pressures made in the apparatus represented in $F_{1 g} 2$ extend from about 45 atms at $1336^{\circ}$ abs to the critical temperature $19103^{\circ}$ The low pressure measurements extend from about 75 degrees above the triple point ${ }^{6}$ temperature to about $1146^{\circ}$

The higher pressure measurements consist of two series presented in Table I The low pressures were measured in a small cryostat whose diameter $(67 \mathrm{~cm})$ was small compared with the length $(30 \mathrm{~cm})$ Efficiency of stirring of the bath fluid of propane and butane is necessary before the experimental tube can be assumed to be at the same temperature as the thermometer

4 Onnes and Braak, Leiden Comm No 107a, 1908

5 Henning, Ann d Phy. 43, 289, 1914

6 Crommelin, Com Leiden Phys Lab No 131, 1912 The temperature of the triple point is given as -18315 and the pressure $70 \mathrm{~cm}$ 
TABLE I

Methane Vapor Pressures

\begin{tabular}{|c|c|c|c|c|c|}
\hline \multirow[b]{2}{*}{$\begin{array}{c}\text { Temperature } \\
\text { Abs }\end{array}$} & \multicolumn{2}{|c|}{ Sernes 1} & \multirow[b]{2}{*}{$\begin{array}{c}\text { Temperature } \\
A b s\end{array}$} & \multicolumn{2}{|c|}{ Sernes 2} \\
\hline & $\begin{array}{c}\text { Observed } \\
\text { Pressure } \\
\text { Atms }\end{array}$ & $\begin{array}{c}\text { Calc } \\
\text { Pressure } \\
\text { Atms }\end{array}$ & & $\begin{array}{c}\text { Obserzed } \\
\text { Pressure } \\
\text { Atms }\end{array}$ & $\begin{array}{c}\text { Calc } \\
\text { Pressure } \\
\text { Atms }\end{array}$ \\
\hline $\begin{array}{l}133628 \\
138558 \\
143495 \\
148439 \\
153385 \\
158339 \\
163295 \\
172437 \\
178189 \\
181203 \\
186147\end{array}$ & $\begin{array}{r}4514 \\
5874 \\
7590 \\
9579 \\
11949 \\
14669 \\
17897 \\
25146 \\
30486 \\
33700 \\
39511\end{array}$ & $\begin{array}{r}4493 \\
5880 \\
7558 \\
9565 \\
11936 \\
14711 \\
17928 \\
25146 \\
30626 \\
33812 \\
39525\end{array}$ & $\begin{array}{r}143380 \\
158549 \\
168267 \\
168351 \\
172355 \\
178189 \\
181203 \\
186084 \\
186147 \\
188005 \\
189931 \\
191031 \\
\text { Crit }\end{array}$ & $\begin{array}{r}7574 \\
14634 \\
21737 \\
21707 \\
25004 \\
30500 \\
33684 \\
39626 \\
39389 \\
41807 \\
44207 \\
46063\end{array}$ & $\begin{array}{r}7515 \\
14839 \\
21637 \\
21704 \\
25073 \\
30626 \\
33812 \\
39449 \\
39525 \\
41835 \\
44326 \\
45792\end{array}$ \\
\hline
\end{tabular}

TABLE II

Low Vapor Pressure Measurements of Methane

\begin{tabular}{|c|c|c|c|c|c|c|c|c|}
\hline$T$ & $\begin{array}{c}\text { Sernes } 1 \\
\text { Pres- } \\
\text { sures } \\
\text { Atms }\end{array}$ & Sernes 2 & Series 3 & Series 4 & Series 5 & 5 Serzes 6 & $\begin{array}{c}\text { Mean } \\
\text { of } \\
\text { Serves } \\
4,5,6\end{array}$ & $\begin{array}{c}\text { Pres- } \\
\text { sure } \\
\text { Calc by } \\
\text { Equa- } \\
\text { tonn }\end{array}$ \\
\hline $\begin{array}{r}97293 \\
100902 \\
106003 \\
110023 \\
114631\end{array}$ & $\begin{array}{l}02638 \\
03855 \\
0 \quad 6276 \\
0 \quad 8925 \\
12917\end{array}$ & $\mid \begin{array}{ll}0 & 2625 \\
0 & 3847 \\
0 & 6271 \\
0 & 8928 \\
1 & 2903\end{array}$ & $\begin{array}{ll}0 & 2620 \\
0 & 3815 \\
0 & 6228 \\
0 & 8858 \\
1 & 2860\end{array}$ & $\begin{array}{l}02575 \\
03774 \\
0 \quad 6216 \\
0 \quad 8839 \\
12846\end{array}$ & $\begin{array}{l}02575 \\
03785 \\
0 \quad 6210 \\
0 \quad 8852\end{array}$ & $\begin{array}{ll}0 & 2571 \\
0 & 3781 \\
0 & 6197 \\
0 & 8829 \\
1 & 2812\end{array}$ & $\mid \begin{array}{ll}0 & 2574 \\
0 & 3780 \\
0 & 6208 \\
0 & 8840 \\
1 & 2829\end{array}$ & $\begin{array}{ll}0 & 2574 \\
0 & 3780 \\
0 & 6196 \\
0 & 8830 \\
1 & 2823\end{array}$ \\
\hline
\end{tabular}

Table II gives the low pressure senes The resistance bridge, in each series of measurements, made at different tımes, was brought to the same indication and the bath regulated at the corresponding temperature In this manner the various changes in the external conditions affecting the measurements could be investigated It was found necessary to increase the speed of the stirring of the bath markedly to secure constancy of the vapor pressure and also the agitation of the liquid methane by means of the electro-magnetic stirrer To establish the absence of hydro- 
gen or air the vapor phase of the methane could be pumped off from time to time during the measurements, and at the conclusion of the day's run from the frozen methane in the steel container before closing the steel cock $\mathrm{K}$ The three final series 4,5 , and 6 show equilibrum was attained and these values have been used to form the mean pressure upon which the equation for the vapor pressure as a function of the temperature was based

Some disappointment was felt that the measurements at higher pressures presented in Table 1 were not more concordant This is not due to any lack of sensitiveness in the pressure-measuring device or lack of constancy in the temperature of the cryostat It is believed to be due possibly to lack of sufficient stirring or agitation of the liquid methane under measurement The construction of the apparatus and the purpose it had to serve precluded an effective stirning device, but a form of stirrer is being perfected which may permit the full utilization of the sensitiveness of the present pressure-measuring apparatus

The equation used to relate the pressure to the temperature is of the form employed for ammonia and carbon dioxide

$$
\log p=-\frac{a}{T}+m+b T+c T^{2}+d T^{3}+\ldots
$$

The evaluation of the constants of this equation can sometimes, as was illustrated in the case of ammonia and carbon-dioxide, be best attained by using the equation in the "critical-constants" form ${ }^{7}$

$$
\log p=-\frac{Z\left(T_{c}-T\right)^{2}+\omega}{T}+m
$$

In the case of methane, however, it was found to be preferable to select the approximate equation $\log p=-\frac{a^{\prime}}{T}+m^{\prime}$ and, by comparng the calculated with the observed logarithms of the pressures, obtain values designated as

$$
\Delta \log p=\log p \text { obs }-\log p \text { calc }
$$

These values were then plotted with the reciprocal of the cor-

7 Thermodynamic Properties of Ammonia Keyes and Brownlee, Wiley \& Sons, page 10, 1916 
responding absolute temperatures and the best curve drawn to represent the final relation The curve was then represented by means of the equation

$$
\Delta \log p=-\frac{\Delta a}{T}+\Delta m+b T+c T^{2}+d T^{3}
$$

where $\Delta a$ and $\Delta m$ are constants which can be used in comparing with the approximate equation to give the final equation for $\log p$ as a function of the absolute temperature The final equation is as follows where $T=(t+27313)$

$$
\begin{aligned}
\log _{10} p^{\mathrm{atm}}= & -\frac{595546}{T}+809938-404175 \times 10^{-2} T+168655 \times 10^{-4} T^{2} \\
& -251715 \times 10^{-7} T^{3}
\end{aligned}
$$

TABLE III

Methane Vapor Pressure Data

\begin{tabular}{c|c|c|c|c|c}
\hline \hline Temperature & $\begin{array}{c}\text { Vapor } \\
\text { Pressure } \\
\text { Calc. } \\
\text { Abs. }\end{array}$ & $\begin{array}{c}\text { Temperature } \\
\text { Deg } \\
\text { Atms. }\end{array}$ & $\begin{array}{c}\text { Vapor } \\
\text { Pressure } \\
\text { Calc } \\
\text { Atms. }\end{array}$ & $\begin{array}{c}\text { Temperature } \\
\text { Deg } \\
\text { Abs }\end{array}$ & $\begin{array}{c}\text { Vapor } \\
\text { Pressure } \\
\text { Calc } \\
\text { Atms }\end{array}$ \\
\hline 9500 & 01982 & 12500 & 2670 & 16000 & 1574 \\
100.00 & 03444 & 13000 & 3.641 & 16500 & 1914 \\
105.00 & 05646 & 13500 & 4853 & 170.00 & 2305 \\
11000 & 08813 & 14000 & 6338 & 17500 & 2749 \\
11152 & 10000 & 14500 & 8132 & 18000 & 3251 \\
11500 & 1319 & 150.00 & 1027 & 18500 & 3815 \\
120.00 & 1905 & 155.00 & 1279 & 19000 & 4442 \\
& & & & 191.03 & 4579 \\
\hline
\end{tabular}

In Table III will be found the vapor pressures in atmospheres for each five degrees beginning with $95^{\circ}$ abs and ending with the critical pressure The critical temperature and pressure were directly observed and may be compared with the value given by Cardoso* of $-82^{\circ} 85$, as compared with $-82^{\circ} 10$ obtained in the present investigation

Cardoso worked under great difficulties in connection with his thermometry and exercised the greatest care and skill in the construction of his pentane thermometers Difficulties were encountered also in connection with the lag in the expansion and

* Cardoso, Jour. de Chim Phys 13, 332, 1915. 
contraction of the glass comprising the thermometers, so that in spite of all the precautions taken errors of temperature were difficult to avord

In Table IV will be found the pressures given by Cardoso at the temperature observed with his pentane thermometer The pressure measurements were made with a closed manometer, using the usual precautions to insure accuracy It w1ll be noted in the table that the Cardoso pressures are uniformly higher than those calculated by the Equation (3) and that the differences in temperature corresponding thereto are roughly the same order of magnitude, except the datum at $17614^{\circ}$ The average temperature difference amounts to $056^{\circ}$ and this correction applied to Cardoso's temperatures would bring the corresponding pressures into fair accord with the present measurements * It will be noted in the

TABLE IV

Cardoso Vapor Pressure Data

\begin{tabular}{l|r|r|r|r|r|r}
\hline \multicolumn{1}{c|}{18874} & 18754 & 18514 & 18214 & 17814 & 17614 \\
\hline$p_{\text {Cardoso }}^{\text {atms }}$ & 4385 & 4203 & 3888 & 3540 & 3100 & 2940 \\
\hline$p_{\text {cal }}^{\text {atms }}$ & 43226 & 41242 & 38312 & 34847 & 30577 & 28586 \\
\hline$\Delta p$ & 624 & 788 & 568 & 553 & 422 & 814 \\
\hline$\Delta T$ & 49 & 63 & 48 & 49 & 42 & 84 \\
\hline
\end{tabular}

Mean $\Delta T=056$

Correcting $T$ crit of Cardoso gives -8229

$T$ crit M I T -8211

Olszewsk1 $1885 \quad-818$

$p$ crit Cardoso $\quad 456$ atms \pm 01

$p$ crit M I T $\quad 458$ atms

* Cardoso, in verifying the readings of his pentane thermometer, used the freezing point of toluene, accepting a value for the freezing point, due to Timmermans, in 1912, of -945 . In this laboratory, there has been found for pure toluene -95.70 referred to the $\mathrm{H}_{2}$ constant volume scale Recently Timmermans, Van der Horst and Onnes (Chem Ab June 10, p. 1694, 1922) give -951 . 
table that the critical pressure given by Cardoso is in good agreement with the pressure observed in this investigation The temperature of the critical condition would, of course, be independent of any thermometer and a correction of 056 applied to the critical temperature, as observed with the pentane thermometer, would give -8229 , which is not in bad agreement with -8211 obtained in these measurements, since the temperature of the critical phenomenon is difficult to locate exactly and, moreover Cardoso has shown that it is best to stir the liquid in observing

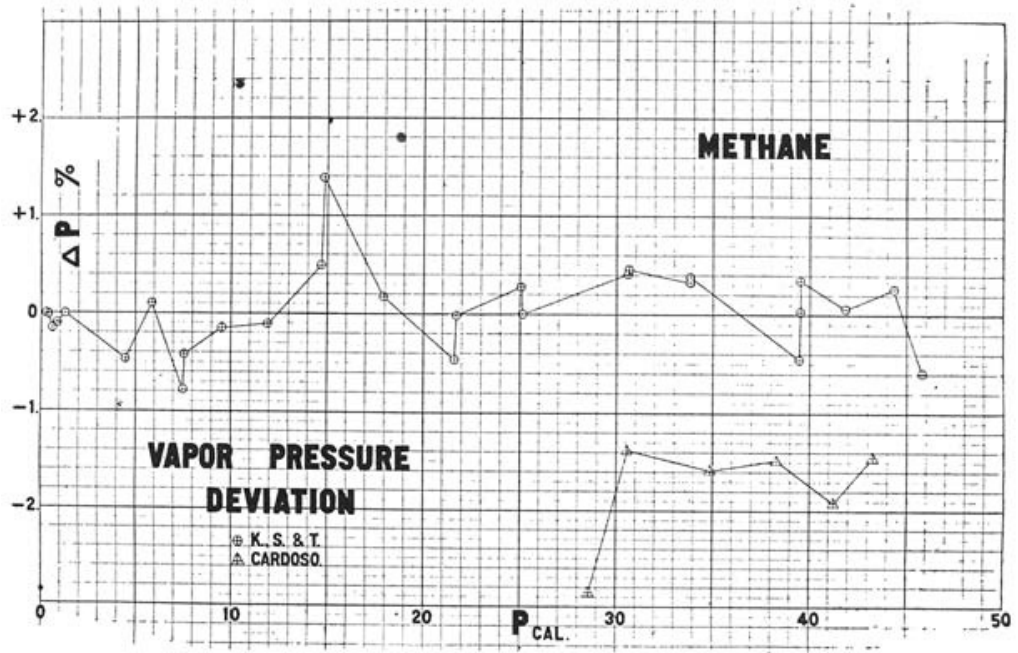

Fig. 4

the critical temperature, whereas in this work no stirring was employed In the section wherem the densities of liquid methane are presented it will be shown that a correction of about $06^{\circ}$ in Cardoso's temperature brings his densities into good agreement with the new values

In Fig 4 the deviations of the individual pressure measurements of Tables 1 and 2 from the pressures calculated by means of Equation (3) are presented The results obtained by Cardoso have been also inserted It is evident that Equation (3) represents the new measurements as satisfactorily as can be expected 


\section{The Specific Volumes of the Liquid and Vapor Phases.} The apparatus, F1g 2, used to measure the liquid spectic volumes has already been described in connection with the vapor pressures The method is of general applicability for the measurement of the hquid specific volumes for all substances whose critical temperature lies below the freezing point of mercury The procedure, however, of confining the liquid in the volumenometer $\mathrm{E}$ by means of the gas phase requires that the mass of fluid in the gas phase, including that portion in the reservorr $\mathrm{F}$, be determinable from a knowledge of its pressure, volume and temperature This requirement has been met, in the present instance, from a knowledge of the methane equation of state, but empincal use of the expermmental isotherms of gaseous methane could also be made

The volume of the volumenometer between the engraved marks on the capillanes was $15798 \mathrm{cc}$, while the used volume of the reservo1r was about $56 \mathrm{cc}$ The total quantity of methane employed amounted to about $066 \mathrm{~g}$ to $078 \mathrm{~g}$, most of which would reside in the volumenometer at the lowest temperatures, but in the bell $\mathrm{F}$ at the highest Owing to the relatively large fraction of the total mass of methane being contained in the reservoir and in the capillary leads of the volumenometer, the accuracy of the specific volume measurements becomes rapidly imparred near the critical temperature Measurements, however, were carried out to 19038 or within about 065 degree of the critical temperature The latter temperature was observed directly, but the reliability of the observation would have been much enhanced by stirnng the fluid, as has been pointed out in particular by Cardoso

The actual density measurements for the two series of measurements are presented in Table $\mathrm{V}$ For the greater part two observations at the same temperature setting were made at different times, which give a means of judging of the reproducibility of the method It will be observed that the concordance is satisfactory on the whole, although in some instances $\left(18120^{\circ}\right.$, Series A) a large difference (one part in 230) occurs On the average, however, one part in fifteen hundred or better is attainable in individual measurements The entire range of the liquid phase has been practically covered and the " smoothed values" are those obtained 
TABLE V

Methane Liquid Densities

\begin{tabular}{|c|c|c|c|c|c|}
\hline \multicolumn{3}{|c|}{ Series $A$} & \multicolumn{3}{|c|}{ Sernes $B$} \\
\hline $\begin{array}{c}\text { Temperature } \\
\text { Deg } \\
A b s\end{array}$ & $\begin{array}{c}\text { Density } \\
\text { Liquid } \\
g m / c c . \\
\text { Obs. }\end{array}$ & $\begin{array}{c}\text { Density } \\
\text { Liquid } \\
\text { gm/c.c. } \\
\text { Smoothed }\end{array}$ & $\begin{array}{c}\text { Temperature } \\
\text { Deg. } \\
\text { Abs. }\end{array}$ & $\begin{array}{c}\text { Density } \\
\text { Liquid } \\
\text { gm./c.c. } \\
\text { Obs. }\end{array}$ & $\begin{array}{c}\text { Density } \\
\text { Liquid } \\
\mathrm{gm} / \mathrm{cc} \text {. } \\
\text { Smoothed }\end{array}$ \\
\hline $\begin{array}{l}186143 \\
186143 \\
181203 \\
181203 \\
178189 \\
178189 \\
172437 \\
172437 \\
168351 \\
168351 \\
163295 \\
163295 \\
158339 \\
158339 \\
153385 \\
153385 \\
148439 \\
143495 \\
143495 \\
138558 \\
138558 \\
133628 \\
133628 \\
128704 \\
128704\end{array}$ & $\begin{array}{r}2505 \\
.2504 \\
2768 \\
2756 \\
.2882 \\
2879 \\
3067 \\
.3067 \\
.3186 \\
.3185 \\
3312 \\
3313 \\
.3429 \\
.3426 \\
3531 \\
3531 \\
.3631 \\
3752 \\
.3750 \\
.3828 \\
.3832 \\
3907 \\
.3909 \\
3985 \\
.4000\end{array}$ & $\begin{array}{l}2504 \\
.2504 \\
.2762 \\
.2762 \\
.2881 \\
.2881 \\
.3067 \\
3067 \\
3182 \\
3182 \\
.3312 \\
.3312 \\
.3429 \\
.3429 \\
.3540 \\
.3540 \\
.3644 \\
.3741 \\
.3741 \\
.3829 \\
.3829 \\
3910 \\
.3910 \\
.3987 \\
3987\end{array}$ & $\begin{array}{l}128562 \\
128562 \\
123911 \\
123.911 \\
119.249 \\
119.249 \\
114.631 \\
114631 \\
110023 \\
110023 \\
106003 \\
105451 \\
100.903 \\
153193 \\
158171 \\
181100 \\
186054 \\
187.974 \\
188937 \\
189902 \\
190.381\end{array}$ & $\begin{array}{l}.3980 \\
.3979 \\
.4051 \\
4049 \\
4129 \\
.4127 \\
.4196 \\
.4195 \\
4266 \\
4262 \\
4313 \\
.4329 \\
.4394 \\
.3542 \\
.3439 \\
.2768 \\
.2510 \\
.2366 \\
2279 \\
2170 \\
.2093\end{array}$ & $\begin{array}{r}.3989 \\
.3989 \\
4059 \\
.4059 \\
.4128 \\
.4128 \\
4196 \\
.4196 \\
.4263 \\
4263 \\
.4321 \\
.4329 \\
.4394 \\
3544 \\
.3433 \\
.2766 \\
.2509 \\
.2375\end{array}$ \\
\hline
\end{tabular}

by plotting the densities rather than the spectic volumes Two densities at the extreme temperature ends of the liquid phase were chosen, and a linear equation determined from which deviations of each observed datum could be computed By plotting these deviations with the corresponding temperatures a smooth curve could be drawn, from which the values tabulated as smoothed were read The device is evidently equivalent to the construction of a very large plot of the observed data

There have been found in the literature only the data of Cardoso already briefly referred to in the section dealing with the vapor pressure It was pointed out in the latter section that the temperatures recorded by Cardoso appeared by comparison of the 
TABLE VI

The Cardoso Saturation Specific Volumes

\begin{tabular}{|c|c|c|c|c|c|c|}
\hline$T$ & $\begin{array}{c}V_{1} \\
\text { Cardoso }\end{array}$ & $\begin{array}{c}V_{2} \\
\text { Cardoso }\end{array}$ & $\begin{array}{c}V_{1} M I T \\
\text { from Mean } \\
\text { Dens Equa }\end{array}$ & $V_{2} M . I T$ & $\begin{array}{l}\text { Cardoso } \\
V_{1} \text { Corr }\end{array}$ & $\begin{array}{l}\text { Cardoso } \\
V_{2} \text { Corr }\end{array}$ \\
\hline $\begin{array}{ll}166 & 1 \\
173 & 1 \\
178 & 1 \\
179 & 1 \\
183 & 1 \\
187 & 1 \\
188 & 1 \\
189 & 1\end{array}$ & $\begin{array}{rl}32 & 05 \\
23 & 20 \\
18 & 80 \\
17 & 18 \\
14 & 73 \\
10 & 96 \\
10 & 08 \\
9 & 15\end{array}$ & $\begin{array}{ll}3 & 085 \\
3 & 307 \\
3 & 500 \\
3 & 559 \\
3 & 791 \\
4 & 198 \\
4 & 371 \\
4 & 628\end{array}$ & $\begin{array}{ll}32 & 85 \\
23 & 75 \\
19 & 02 \\
18 & 15 \\
15 & 05 \\
12 & 25\end{array}$ & $\begin{array}{ll}3.076 \\
3 & 280 \\
3 & 465 \\
3 & 510 \\
3 & 732 \\
4 & 110\end{array}$ & $\begin{array}{ll}32 & 92 \\
23 & 80 \\
19 & 29 \\
17 & 65 \\
15 & 15 \\
11 & 33\end{array}$ & $\begin{array}{ll}3 & 071 \\
3 & 288 \\
3 & 476 \\
3 & 532 \\
3 & 752 \\
4 & 147\end{array}$ \\
\hline
\end{tabular}

pressures to differ by $056^{\circ}$ from the temperature scale used in this investigation A shift in the Cardoso temperature scale of equal amount in this instance also brings the latter's observations into agreement with those here presented, thus confirming the opinion already stated that it is the temperature scales which are in disagreement rather than the pressure or volume measurements In Table VI the second column gives the vapor volumes as given for the temperatures spectied by Cardoso The third column gives the Cardoso liquid volumes Columns four and five contain the vapor and liquid volumes obtained in the present investigation at the same temperatures, and the sixth and seventh columns, the volumes of Cardoso corrected for the temperature difference 056 It is seen that substantial agreement is obtained, as was the case with the vapor pressures

The specific volumes of the saturated vapor have always been exceedingly difficult to measure The difficulty of obtaining true equilibruum, freedom from foreign gases, the complete drainage of the walls of the container, the relatively large fraction of the total mass necessarily present in the liquid phase, and surface adsorption are some of the difficulties encountered Experimental experience has led almost to the conviction that the vapor specific volume cannot be accurately measured In the case of ammonia it was found that the equation of state gave saturated vapor specific volumes which accorded with the actual observation within the unavoidable errors of experiment and the same statement is true as regards carbon doxide ${ }^{9}$ At the low temperatures

9 Keyes and Kenney, Jour of Soc Am Ref Engr , 3, 1, 1917 


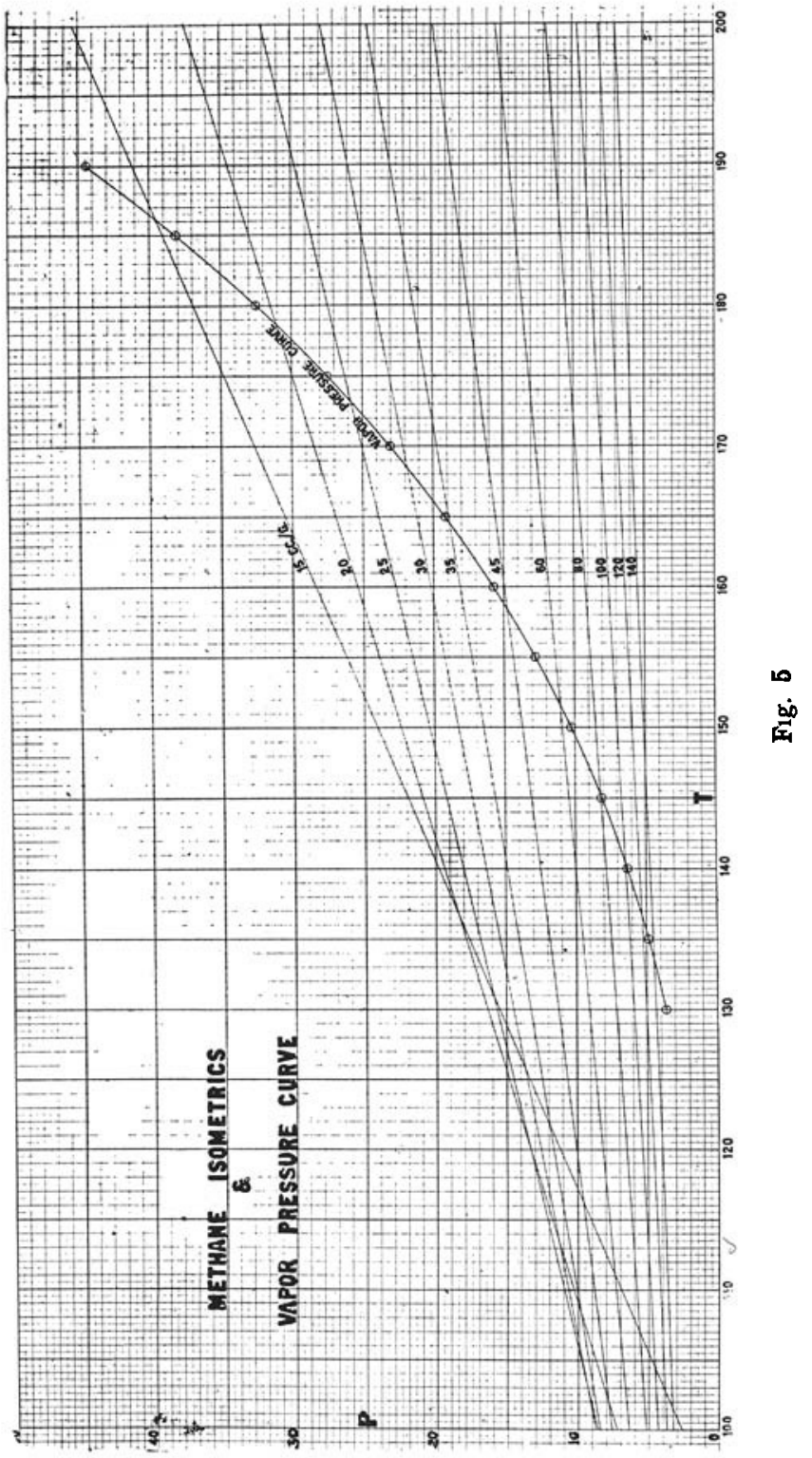


encountered in the liquid range of methane some apprehension was felt concerning the reliability of using the methane equation of state to calculate the saturation specific volumes, but the enhanced difficulties of carrying out measurements at such low temperatures lead to the decision to calculate the volumes In the case of nitrogen whose equation of state we possess, values are obtained which, when employed in the Clapeyron equation, give a value for the latent heat of vaporization agreeng well with the experimental number It 1s, of course, evident that for the very large specific volumes $(1,000 \mathrm{cc} / \mathrm{g})$ the equation of state would be accurate The doubt which may arise pertains to volumes from $200 \mathrm{c} \mathrm{c} / \mathrm{g}$ to $30 \mathrm{c} \mathrm{c} / \mathrm{g}$

The plot of a number of the isometrics of methane is represented in Fig 5, upon which has been placed the vapor pressures The saturation specific volumes are the points of intersection of the 1sometrics with the pressure-temperature curve and this 1s, perhaps, the most convenient means of obtaining the vapor specific volumes The final specific volumes for both phases are represented in the plot Fig 6

Table VII contains the saturation specific volumes and densities of methane vapor and hquid from $95^{\circ}$ to the critical temperature for each five degrees Volumes smaller than $35 \mathrm{cc} / \mathrm{g}$ were not

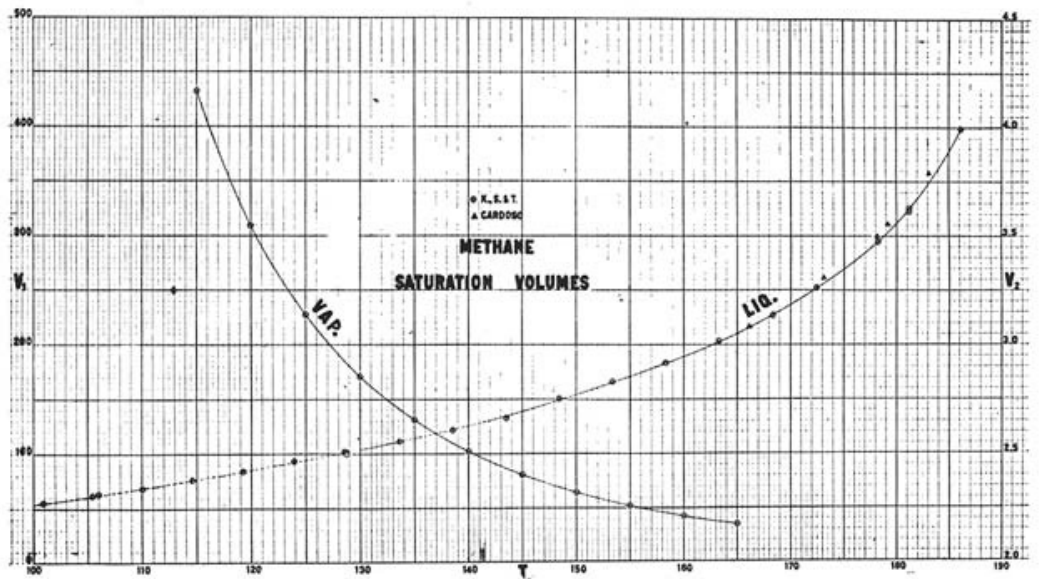

Fig. 6 
computed, since association or polymerization may be supposed to exist in the smaller volumes and the equation of state applies only for the case where the completely unassociated methane molecules are present The mean diameter equation can be used to obtain volumes smaller than $35 \mathrm{c} \mathrm{c} / \mathrm{g}$

TABLE VII

M. I. T. Methane Data

\begin{tabular}{|c|c|c|c|c|c|}
\hline $\begin{array}{c}\text { Temp } \\
\text { Deg } \\
A b s\end{array}$ & $\begin{array}{l}\text { Specrfic } \\
\text { Volume } \\
\text { Liquid } \\
\text { cc/gm }\end{array}$ & $\begin{array}{c}\text { Spectfc } \\
\text { Volume } \\
\text { sat'd vapor } \\
\text { Keyes'eq } \\
\text { cc/gm }\end{array}$ & $\begin{array}{l}\text { Density } \\
\text { Liquid } \\
g m / c c\end{array}$ & $\begin{array}{c}\text { Density } \\
\text { sat'd vapor } \\
\text { Keyes' } E q \\
\text { gm / c }\end{array}$ & $\begin{array}{c}\text { Density } \\
\text { sat'd vapor } \\
\text { from dm } \\
\text { and Itquid } \\
\text { Density } \\
\mathrm{gm} / \mathrm{c} c\end{array}$ \\
\hline $\begin{array}{l}95 \\
100 \\
105 \\
110 \\
11152 \\
115 \\
120 \\
125 \\
130 \\
135 \\
140 \\
145 \\
150 \\
155 \\
160 \\
165 \\
170 \\
175 \\
180 \\
185 \\
190 \\
19103 \\
\text { Crit }\end{array}$ & $\begin{array}{ll}2 & 2691 \\
2 & 3069 \\
2 & 3458 \\
2 & 3580 \\
2 & 3865 \\
2.4291 \\
2 & 4735 \\
2 & 5208 \\
2 & 5719 \\
2 & 6288 \\
2 & 6937 \\
2 & 7683 \\
2 & 8533 \\
2 & 9491 \\
3 & 0496 \\
3 & 1881 \\
3 & 3463 \\
3 & 5565 \\
3 & 8871 \\
& \end{array}$ & $\begin{array}{r}24367 \\
14704 \\
936.9 \\
6247 \\
5569 \\
432.7 \\
3094 \\
227.4 \\
1710 \\
1310 \\
1021 \\
80.63 \\
6443 \\
5196 \\
4222 \\
3449\end{array}$ & $\begin{array}{l}.4417 \\
4335 \\
4263 \\
.4241 \\
4190 \\
.4117 \\
4043 \\
3967 \\
3888 \\
.3804 \\
.3712 \\
.3612 \\
3505 \\
.3391 \\
.3279 \\
.3137 \\
2988 \\
2812 \\
2573 \\
.1613\end{array}$ & $\begin{array}{c}0004104 \\
0006801 \\
001067 \\
.001601 \\
001796 \\
002311 \\
.003232 \\
.004398 \\
.005850 \\
.007632 \\
009794 \\
.01240 \\
01552 \\
.01925 \\
.02369 \\
.02899\end{array}$ & $\begin{array}{l}.03667 \\
.04592 \\
.05598 \\
.07335 \\
.1613\end{array}$ \\
\hline
\end{tabular}

The data of Cardoso relative to the saturation volumes were taken close to the critical temperature However, in the range where the specific volumes were computed by means of the equation of state the following mean density equation was obtained

$$
D m=016134+000065723\left(T_{c}-T\right)
$$

Cardoso gives the mean density equation based on his results,

$$
D m=01623+00006064(T c-T)
$$

The agreement is very good and lends confidence to the computed 
values $F_{1} g$ gives the densities obtaned in the present investigation together with the uncorrected Cardoso values The critical density, making the temperature correction 056 , makes the critical density of Cardoso 01618 , as compared with 01613 obtained in the present investigation

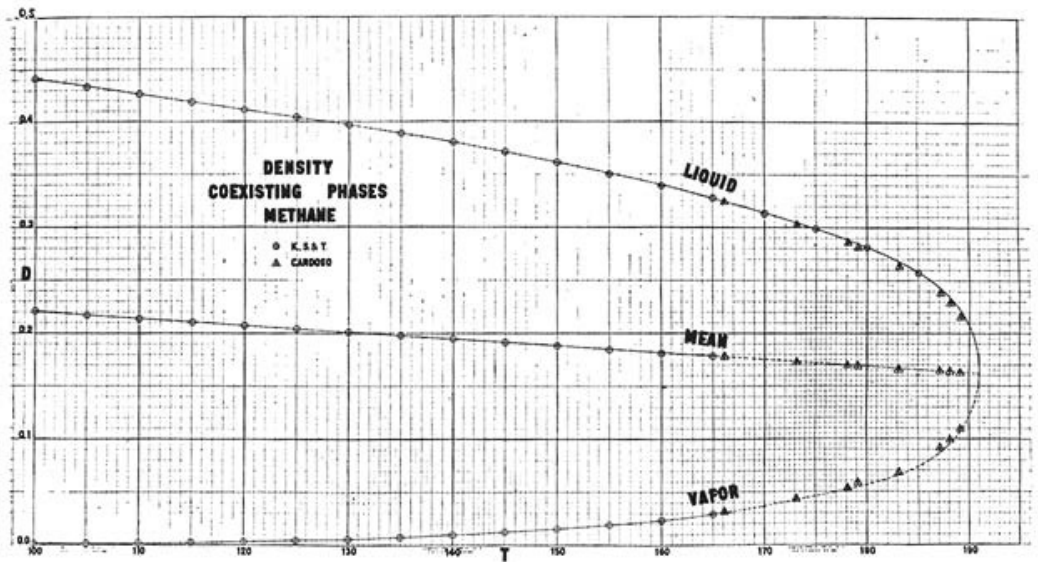

Fig. 7

6 The Latent Heats of Evaporation. A prelıminary study has been made in the development of calonmetric methods that will permit the measurement of heats of evaporation and the specific heats of liquids at very low temperatures At present, however, no experimental values are avallable for methane, but by means of the vapor pressure equation and the specific volumes of the coexisting phases, latent heats may be calculated by means of the Clapeyron equation

The equation of the vapor pressure, (3), upon differentiation gives for $\frac{d p}{d t}$,

$\frac{d p}{d T}=p\left[\frac{1371298}{T^{2}}-0093065+776685 \times 10^{-4} T-173878 \times 10^{-6} T^{2}\right]$

In Table VIII will be found in the first column the absolute temperature and in the succeeding columns the value of $\frac{d p}{d T}$, 
TABLE VIII

Latent Heat of Evaporation

\begin{tabular}{l|c|r|c|c|c}
\hline \hline \multicolumn{1}{c|}{$T$} & $\frac{d p}{d T}$ atms & $V_{1} \frac{c c}{g}$ & $V_{2} \frac{c c}{g}$ & $\lambda \frac{c a l}{g}$ & calc \\
\hline 100 & 003593 & 14704 & 22691 & 12775 & 12759 \\
105 & 005290 & 9369 & 23068 & 12571 & 12571 \\
110 & 007461 & 6247 & 23458 & 12369 & 12376 \\
11152 & 008214 & 5568 & 23580 & 12299 & Normal \\
115 & 010152 & 4327 & 23868 & 12165 & 12174 \\
120 & 013403 & 3094 & 24291 & 11958 & 11964 \\
125 & 017249 & 2274 & 24735 & 11744 & 11744 \\
130 & 021723 & 1710 & 25208 & 11519 & 11514 \\
135 & 026856 & 1310 & 25719 & 11279 & 11271 \\
140 & 032677 & 1027 & 26288 & 11020 & 11014 \\
145 & 039214 & 806 & 26937 & 10732 & 10739 \\
150 & 046493 & 644 & 27683 & 10414 & 10444 \\
155 & 054535 & 5196 & 28533 & 10052 & 10123 \\
160 & 063363 & 4222 & 29491 & 9642 & 9770 \\
165 & 072975 & 3449 & 30496 & 9168 & 9374 \\
\hline \hline
\end{tabular}

$V_{1}, V_{2}$ and the latent heat $O n$ the basis of these latent heat values the following equation was composed relating the quantity to the temperature

$\log _{10} \lambda=165214+20076 \times 10^{-4}(T c-T)+022225 \log _{10}\left(T_{c}-T\right)$.

There are no published data for the latent heat of evaporation of methane with the exception of an approximate value recently obtained due to Satterly and Patterson ${ }^{10}$ who give $138 \mathrm{cal} / \mathrm{g} \pm 5 \%$ Th1s value refers to the temperature of the normal boiling point $11152^{\circ}$ at which temperature $123 \mathrm{cal} / \mathrm{g}$ is obtained in the present investigation The experimental value is about ten per cent greater The value of the mean specific heat of copper is involved in the measurement and an error in the true boiling point of methane enters in computing the latent heat from the expenmental data The methane evolved by the copper block dropped into the hquid was measured by collecting over water In a later paper experimental values obtained in this laboratory will be presented

If the liquid phase consisted of completely polymerized double molecules or, in fact, was composed of molecules whose molecular

10 Satterly and Patterson, Roy Soc Can Trans 13, 123, 1919 
species was constant with respect to temperature changes the internal heat of evaporation would be simply related to the specific volumes of the coexisting phases Consider the thermodynamic equation:

$$
\left(\frac{\partial U}{\partial V}\right)_{T}=T\left(\frac{\partial p}{\partial T}\right)_{v} p
$$

Integration of this equation at constant temperature yrelds,

$$
U_{2}-U_{1}=\int_{v_{1}}^{v_{2}}\left(T\left(\frac{\partial p}{\partial T}\right)_{v}-p\right) d v
$$

and for an invariable species composing the liquid phase of specific volume, $v_{2}$, passing to a specific volume $v_{1}$ of the vapor phase the energy is represented by the work against the attractive forces of the molecules Evaluating $\left(\frac{\partial p}{\partial T}\right)_{v}$ by means of the equation of state will give, then, a definite value for the right-hand member of Equation (7)

$$
\int_{v_{1}}^{v_{3}}\left(T \frac{\partial p}{\partial T}-p\right) d v=\int_{v_{1}}^{v_{2}}\left(\frac{R T}{v-\delta}-p\right) d v=\int_{v_{1}}^{v_{2}} \frac{A}{(v-l)^{2}} d v,
$$

or

$$
\Delta U=U_{1}-U_{2}=A\left(\frac{1}{v_{2}-l}-\frac{1}{v_{1}-l}\right) .
$$

Now $\Delta U$ and the specific volumes of the coexisting phases may be plotted with $\frac{1}{\Delta U}$ and $v_{2}$ as coordinates giving a line which may be used as an approximation plot to roughly evaluate $l$ and $A$ and the data replotted, using as coordinates $\frac{1}{\Delta U+\frac{A}{v_{1}}}$ and $v_{2}$ The fact that a straight line is obtained may mean that the molecular state of the liquid is the same as that of the vapor in contact therewith, or 1t may mean that the molecular state of the liquid, for example, was that of substantially complete polymerization to double molecules or those of higher order, the vapor in 
contact consisting of substantially all single molecules The value of $A$ in the latter case would be a certain mean value, then, between the value of $A$ for double molecules and single molecules If the liquid, however, was composed of molecules of the same type as the vapor, the value of $A$ should be numerically equal to

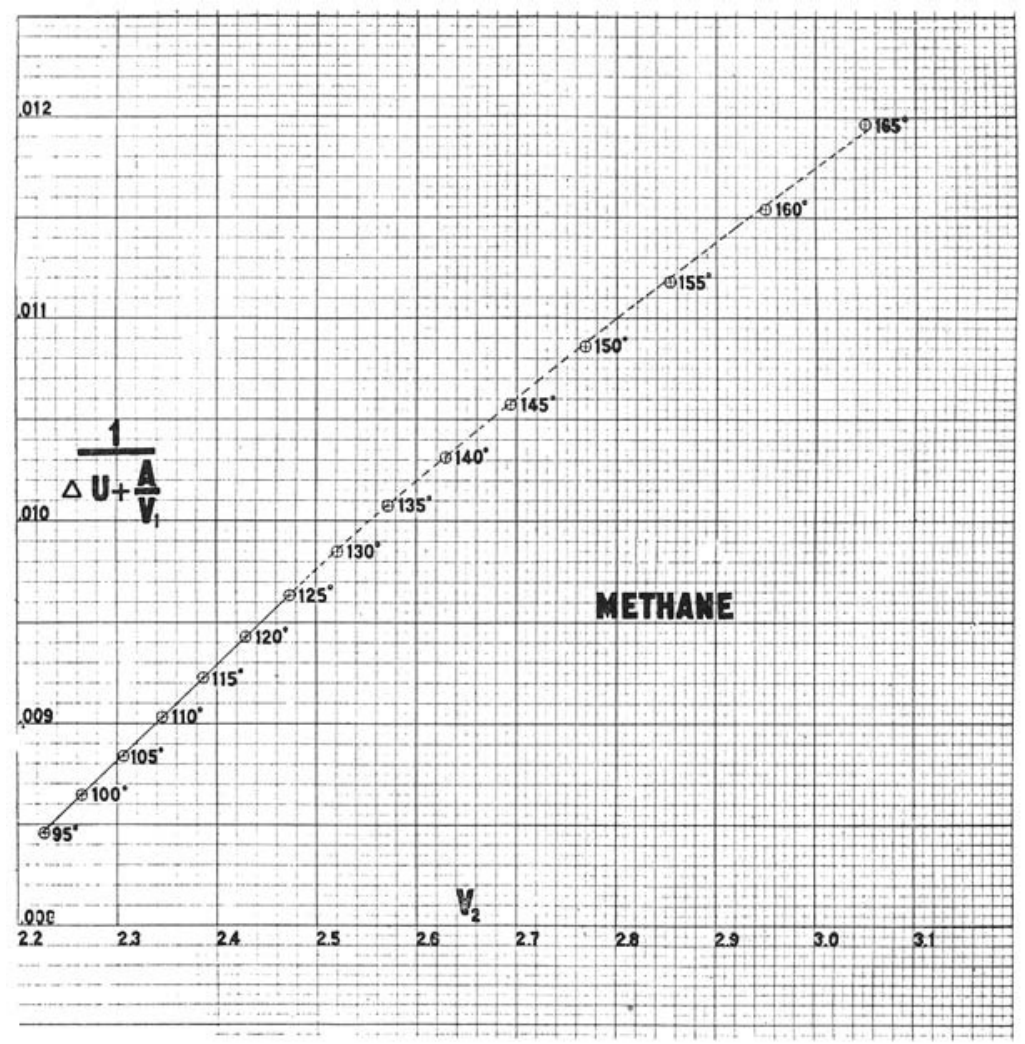

Fig. 8

$A$ obtained for the equation of state of methane Moreover, if the data do not he on a straight line in terms of the coordinates given, evidence is afforded that the relative molecular state in the coexisting phases is changing at higher temperatures As a matter of fact the data of methane in the lower temperature range do lie on a straight line, but deviate as higher temperatures 
are approached Also the numencal value of $A$ is not that found for the equation of state of methane composed of single molecules. Fig 8 exhibits the methane data

The further elaboration of the connection between the internal heat of evaporation and the equation of state has been waiting for some years for the completion of several investigations in progress in this laboratory Very shortly, for example, there will appear the results in connection with liquid ether at low temperatures, which illustrate the linear relation between $\frac{1}{\Delta U+\frac{A}{v_{1}}}$ and $v_{2}$, and further papers, it is hoped, w1ll follow promptly

7 The Specific Heats of the Coexisting Phases. The exper1mental data for the vapor phase have been published by Regnault, ${ }^{11}$ Lussana $^{\mathbf{1 2}}$ and Heuse ${ }^{13}$ The latter data supersede the older work and measurements were made at the temperatures $150,50,-300,-550,-810$ The one atmosphere constant pressure values were computed to constant volume specific heats by means of the equation of state and from a plot values chosen at the absolute temperatures $150,200,250 ; 300$ for the purpose of correlation as a function of the temperature The equation obtained is,

$$
C_{v}=03050+112 \times 10^{-3} T-645 \times 10^{-6} T^{2}+1304 \times 10^{-9} T^{3} .
$$

To obtain the constant pressure specific heat use may be made of the equation

$$
C_{p}=C_{v}+T\left(\frac{\partial p}{\partial T}\right)_{v}\left(\frac{\partial v}{\partial T}\right)_{p}
$$

which becomes using the equation of state for methane

$$
C_{p}=C_{v}+\frac{R / m}{1-\frac{a \delta}{v^{2}}}-\frac{2 A}{R T} \frac{(v-\delta)^{2}}{(v+l)^{3}}
$$

This equation is not valid in the critical region but will give accurate values along the saturation line to at least $35 \mathrm{cc}$ per

11 Regnault. Mem de l'Acad 26, 1, 1862

12 Lussana Nouv Cim 36, 5, 70, 130, 1894

13 Heuse Ann d Phy 59, 94, 1919 
gram For low pressures it suffices to replace (11) by the approximate equation

$$
C_{p}=C_{p_{0}}+\frac{2 A}{R} \cdot \frac{1}{T^{2}} p
$$

where $C_{p_{\mathrm{o}}}$ is the specific heat at very low pressures, being equal to $C_{v}+R / m ; m$ representing the molecular weight in grams and $R$ the gas constant per mol in calories The numerical equation corresponding to (12) 1s,

$$
\begin{gathered}
C_{p}=04288+112 \times 10^{-3} T \\
-6.45 \times 10^{-6} T^{2}+1304 \times 10^{-9} T^{3}+\frac{93}{T^{2}} p^{\text {atm }}
\end{gathered}
$$

In Table IX will be found the comparison of the vapor specific heats computed by Equation (9) and the experimental values due to Heuse

\begin{tabular}{|c|c|c|c|c|c|}
\hline & 150 & 5.0 & -300 & -550 & -810 \\
\hline $\begin{array}{ll}C_{v} & \text { Heuse } \\
C_{v} & \text { Calculated }\end{array}$ & $\begin{array}{l}04051 \\
0.4041\end{array}$ & $\begin{array}{l}0.4000 \\
0.3982\end{array}$ & $\begin{array}{l}0.3826 \\
0.3834\end{array}$ & $\begin{array}{l}03782 \\
03778\end{array}$ & $\begin{array}{l}03777 \\
0.3746\end{array}$ \\
\hline
\end{tabular}

TABLE IX

The Gas Phase Specific Heat

Regnault gives $0593 \mathrm{cal}$ as the value of $C_{p}$ between 18 and 208 at one atmosphere Equation (13), however, leads to $0675 \mathrm{cal}$ Lussana gives 0591 cal between 11 and 95 at one atmosphere, whereas the equation gives $0564 \mathrm{cal}$ Lussana gives the specific heat between 11 and 95 as a function of the pressure, as follows:

$$
C_{p}=05915+003463(p-1)
$$

whereas Equation (13) leads to

$$
C_{p}=05643+000089(p-1) \text {. }
$$

The pressure coefficient of Lussana is nearly forty times as large as that given through the equation of state In the case of aur Lussana's pressure coefficient is also much greater than that given by the equation of state for arr ${ }^{14}$ Holborn and Jacobs, ${ }^{15}$

14 Keyes, Jour. Amer Chem. Soc 43, 1452, 1921

16 Holborn and Jacobs, $Z$ Ver deut Ing. 58, 1429, 1914. 
however, recently measured the specific heat of air to 200 atms. and their mean pressure coefficient agrees almost exactly with that given through the equation of state Carbon dioxide and ammonia furnished further examples and there can be little doubt but that Lussana's pressure coefficients are all too large

Facilities for measuring the specific heat of the liquid phase of substances have been under development for some years and shortly values will be avallable In the meantime use may be made of the available data to calculate the liquid phase specific heat

Consider the thermodynamic equation

$$
C_{s}-C_{s s}=T \frac{d \frac{\lambda}{T}}{d T}
$$

where $C_{s_{1}}$ and $C_{s_{2}}$ denote the specific heat of the saturated gas and liquid phases respectively, while $\lambda$ as before represents the latent heat of evaporation The equation for $C_{s i}$ is,

$$
C_{s_{1}}=C_{p_{1}}-T\left(\frac{\partial v}{\partial T}\right)_{p} \frac{d p}{d T}
$$

and $C_{p_{1}}=C_{v_{1}}+T\left(\frac{\partial p}{\partial T}\right) \cdot\left(\frac{\partial v}{\partial T}\right)$ By means of the equation of state the differential coefficients can be evaluated, while $C_{v}$ is given by the equation (9). The equation for $T \frac{d \frac{\lambda}{T}}{d T}$ can be formed from Equation (5) leading to

$$
T \frac{d \overline{\bar{T}}}{d T}=-\lambda\left[00004623+\frac{022225}{T_{c}-T}+\frac{1}{T}\right] \text {. }
$$

At $110^{\circ} C_{s_{1}}$ is $-0689 \frac{\mathrm{cal}}{\mathrm{g}}$ and $T \frac{d \bar{T}}{d T}$ equal to -1522 , giving $C_{s_{2}}$, the specific heat of the liquid, $0.833 \frac{\mathrm{cal}}{\mathrm{g}}$. At $150^{\circ} C_{s_{1}}$ is $-0489 \frac{\mathrm{cal} \text {. }}{\mathrm{g}}$ and $T \frac{d \hat{\bar{T}}}{d T}$ equal to -1307 giving $0818 \frac{\mathrm{cal}}{\mathrm{g} \text {. }}$ for the liquid specific 
heat. The latter number would be expected to be larger than the former, but the specific heat value at $110^{\circ}$ involves a long extrapolation by means of the gas phase constant volume specific heat Equat1on, (9) All that may be stated at present is that in the region of the boiling point the specific heat of the liquid is about $0.82 \frac{\mathrm{cal} \text {. }}{\mathrm{g} \text {. }}$

\section{SUMMARY}

1 The vapor pressure of methane has been measured over substantrally the entre liquid phase region and correlated as a function of the temperature as follows.

$$
\begin{aligned}
\log _{10} p^{\mathrm{atm} .}=-\frac{595546}{T} & +809938-404175 \times 10^{-2} T+168655 \times 10^{-4} T^{2} \\
& -251715 \times 10^{-7} T^{3} .
\end{aligned}
$$

2 The liquid phase specific volumes have been measured from about $100^{\circ}$ abs to nearly the critical temperature, 19103 abs The saturation specific volumes of the vapor phase were computed by means of the equation of state of methane, using the values of the pressure computed for definite temperatures from the vapor pressure equation.

3 The critical temperature is found to be $19103^{\circ} \mathrm{abs}$ on the scale of the quartz constant volume hydrogen thermometer The critical pressure amounts to $458 \mathrm{atms}$, while the critical volume computed from the mean diameter equation is $62 \mathrm{cc} / \mathrm{g}$

4 The heat of evaporation was computed by the Clapeyron equation, using the derivative $\frac{d p}{d T}$ obtained by differentiation of the vapor pressure equation and the specific volumes of the coexisting phases The following equation reproduces the values from $100^{\circ}$ abs to $150^{\circ}$ abs where $\lambda$ represents the heat of evaporation:

$$
\log _{10} \lambda=165214+20076 \times 10^{-4}\left(T_{c}-T\right)+022225 \log _{10}\left(T_{c}-T\right) .
$$


5 The specific heat of the gas phases may be represented by the following equation based on the experimental values of Heuse:

$$
C_{v}=03050+112 \times 10^{-3} T-645 \times 10^{-6} T^{2}+1304 \times 10^{-9} T^{3} .
$$

6 The specific heat of the saturated liquid was computed by means of the thermodynamic equation

$$
C_{s_{2}}=C_{s_{1}}-T \frac{d \frac{\lambda}{T}}{d T}
$$

and found to be $082 \frac{\mathrm{cal} .}{\mathrm{g} .}$ in the neighborhood of the normal boiling point 